\title{
Simultaneous Determination and Stability Studies on Diminazene Diaceturate and Phenazone Using Developed Derivative Spectrophotometric Method
}

\author{
Ruaa Mohamed Akode, Shaza Wagiealla Shantier, \\ Elrasheed Ahmed Gadkariem, and Magdi Awadalla Mohamed \\ Department of Pharmaceutical Chemistry, Faculty of Pharmacy, University of Khartoum, P.O. Box 1996, Khartoum, Sudan \\ Correspondence should be addressed to Ruaa Mohamed Akode; ruaa.mohd@uofk.edu
}

Received 15 November 2016; Accepted 9 January 2017; Published 26 January 2017

Academic Editor: Frantisek Foret

Copyright ( $) 2017$ Ruaa Mohamed Akode et al. This is an open access article distributed under the Creative Commons Attribution License, which permits unrestricted use, distribution, and reproduction in any medium, provided the original work is properly cited.

\begin{abstract}
This work presents UV first derivative spectrophotometry as a precise, accurate, and feasible method for simultaneous determination of diminazene diaceturate and phenazone in bulk and dosage forms. The absorbance values of diminazene diaceturate and phenazone aqueous mixture were obtained at $398 \mathrm{~nm}$ and $273 \mathrm{~nm}$, respectively. The developed method was proved to be linear over the concentration ranges $(2-10) \mu \mathrm{g} / \mathrm{mL}$ and $(2.496-12.48) \mu \mathrm{g} / \mathrm{mL}$ for diminazene diaceturate and phenazone, respectively, with good correlation coefficients (not less than 0.997 ). The detection and quantitation limits were found to be (LOD $=0.63$ and $0.48 \mu \mathrm{g} / \mathrm{mL}$; $\mathrm{LOQ}=1.92$ and $1.47 \mu \mathrm{g} / \mathrm{mL}$, resp.). The developed method was employed for stability studies of both drugs under different stress conditions. Diminazene diaceturate was prone to degrade at acidic $\mathrm{pH}$ via first-order kinetics. The degradation process was found to be temperature dependent with an activation energy of $7.48 \mathrm{kcal} / \mathrm{mole}$. Photo-stability was also investigated for this drug.
\end{abstract}

\section{Introduction}

The combination therapy of diminazene diaceturate (DD) and phenazone (PHZ) (Figure 1) is prescribed in veterinary field for the treatment of trypanosomiasis and babesiosis. The trypanocide and babesiacide effects mainly return to DD [1]. It is an aromatic diamidine derivative with acidic properties [1]. PHZ is a pyrazolone derivative with basic properties used as anti-inflammatory and stabilizer for DD aqueous preparation since the latter is only stable for $2-3$ days $[2,3]$.

Despite their wide use in developing countries, DD and PHZ formulations have no official method for their routine analysis and stability evaluation. Nevertheless, literature review revealed various methods for their analysis. The majority of the reported methods were concerned with the analysis of these drugs separately in biological fluids or tissues rather than pharmaceutical dosage forms. These methods include different chromatographic, ELISA, and radioassay techniques [4-12]. RP-HPLC and absorption and ratio spectra wavelet approaches were reported for the simultaneous determination of DD and PHZ in pharmaceutical combinations [3,13-15]. The stability profile of DD and PHZ was also assessed using various chromatographic methods $[3,13,16$, 17]. However, most of these methods are tedious and expensive for routine analysis. Besides its simplicity, spectrophotometry and particularly derivatization of normal spectrum (zero order) was shown to have many advantages such as resolution of overlapping peaks and background elimination [18]. These properties make derivatization of spectrum an alternative stability indicating method instead of HPLC.

Therefore, the aim of this work was to develop a feasible, accurate, and precise first derivative spectrophotometric method for the simultaneous determination and stability studies of DD and PHZ in bulk and pharmaceutical dosage forms.

\section{Materials and Methods}

2.1. Instrumentation. All spectrophotometric measurements were conducted on Shimadzu UV 1800 spectrometer (ENG 

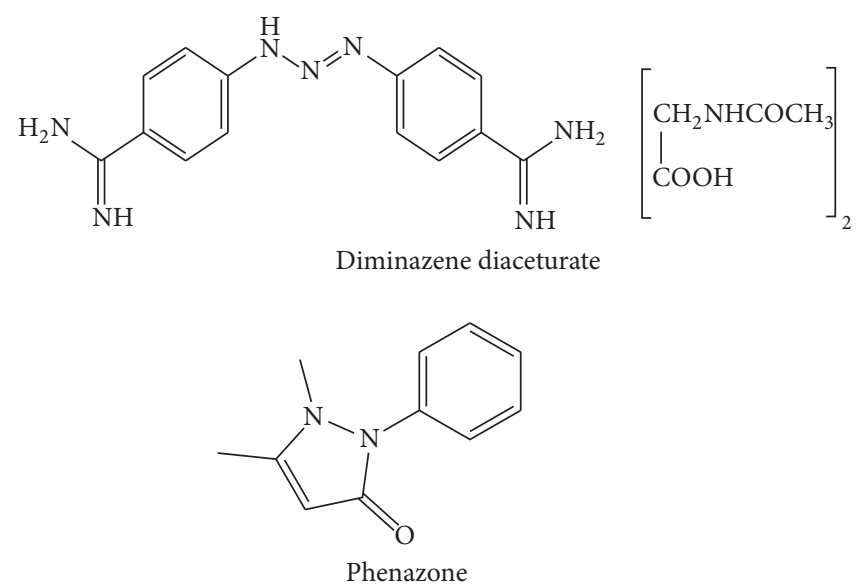

FIGURE 1: Chemical structure of diminazene diaceturate and phenazone.

$240 \mathrm{~V}$, Japan) using quartz cells $(1 \mathrm{~cm})$, scanning range $200-$ $450 \mathrm{~nm}$. Heating was conducted on temperature regulated water bath (YCM-010E, Germany).

2.2. Drugs. Sachet of commercial brands $(2.56 \mathrm{~g})$ consisting of DD (1.05 g) and PHZ (1.31 g) was purchased from local market. Both DD (100.3\%) and PHZ (99.9\%) reference standards were kindly provided by National Drug Quality Control Laboratory.

2.3. Reagents. $\mathrm{NaOH}, \mathrm{HCl}(10 \mathrm{M})$, and $\mathrm{H}_{2} \mathrm{O}_{2}$ (3\%) were of analytical grade (BDH Chemicals Ltd. Poole, UK). McIlvaine buffer ( $\mathrm{pH}$ 2.2) was prepared by mixing citric acid and disodium hydrogen phosphate solutions [19].

2.4. Stock Solutions of Standard and Sample. Standard stock solution consisting of a mixture of DD and PHZ was freshly prepared in distilled water to give a final concentration of $50 \mu \mathrm{g} / \mathrm{mL}$ (DD) and $62.4 \mu \mathrm{g} / \mathrm{mL}$ (PHZ). Samples stock solutions were prepared in similar manner to give the same concentration.

\subsection{Method Validation}

2.5.1. Linearity. Different aliquots of the standard stock solution were diluted to obtain final concentration range of $2-10 \mu \mathrm{g} / \mathrm{mL}$ (DD) and $2.496-12.48 \mu \mathrm{g} / \mathrm{mL}$ (PHZ). The first derivative spectrum was recorded and the absorbance values were plotted against concentrations to obtain the calibration curves. The linearity data was then interpreted from calibration curves derived from five different analytes concentration.

Aliquots of sample stock solution were treated as under linearity. The sample content was calculated by direct comparison of sample/standard absorbance values.

2.5.2. Limits of Detection (LOD) and Quantitation (LOQ). Limits of detection and quantitation were interpreted according to the following equations:

$$
\begin{aligned}
& \mathrm{LOD}=\frac{3.3 \delta}{S} ; \\
& \mathrm{LOQ}=\frac{10 \delta}{S},
\end{aligned}
$$

where $\delta$ is the standard deviation of the intercept of the regression line and $S$ is the slope of the calibration line [20].

2.5.3. Precision and Accuracy. To evaluate method precision, different concentrations were prepared from sample stock solution and analysed three times within the same day and in three separate days to evaluate within-day and betweenday precision, respectively. Recovery studies were conducted to assess the accuracy through spiking of sample $(8 \mu \mathrm{g} / \mathrm{mL}$ (DD); $9.98 \mu \mathrm{g} / \mathrm{mL}(\mathrm{PHZ})$ ) with standard of $50 \%, 100 \%$, and $150 \%$ of the sample concentration $(n=3)$. The following equation was used to calculate $\%$ recovery:

$$
\% \text { recovery }=\frac{\left(A_{\text {mix }}-A_{\text {sam }}\right)}{A_{\text {std }}} \times 100,
$$

where $A_{\text {mix }}$ is the absorbance of the mixture solution, $A_{\text {sam }}$ is the absorbance of the sample solution, and $A_{\text {std }}$ is the absorbance of the standard solution [20].

\subsection{Stability Indicating Studies}

2.6.1. Effect of Acidic, Alkaline, and Oxidative Conditions on Stability of DD Standard Solution. $3 \mathrm{~mL}$ of DD standard solution $(20 \mu \mathrm{g} / \mathrm{mL})$ was mixed with $2 \mathrm{~mL}$ of either $0.05 \mathrm{M} \mathrm{HCl}$ or $0.1-1 \mathrm{M} \mathrm{NaOH}$. The volume was completed to $10 \mathrm{~mL}$ with distilled water. The first derivative spectra were then recorded at suitable time intervals (10 minutes). The effect of oxidative conditions on DD standard solution was investigated by repeating the same procedure using $1 \mathrm{~mL}$ of $1.2 \mathrm{M} \mathrm{H}_{2} \mathrm{O}_{2}$ instead of $\mathrm{NaOH}$ or/and HCL. The responses were recorded every day for three days using the developed method.

2.6.2. Effect of Light on Stability of DD Standard Solution. DD standard solution $(6 \mu \mathrm{g} / \mathrm{mL})$ was placed in transparent and amber glass tubes. The solutions were then subjected to direct sunlight during mid-day time for 4 hours. Another DD standard solution $(6 \mu \mathrm{g} / \mathrm{mL})$ was placed in transparent glass tube and irradiated with UV light ( $254 \mathrm{~nm}$ ) for 24 hours. The degradation process was monitored using the developed method. 
2.6.3. Temperature Effect on Stability of DD Standard Solution. Aliquots of DD standard solution $(3 \mathrm{~mL}, 20 \mu \mathrm{g} / \mathrm{mL})$ were transferred into four stoppered glass tubes. $1 \mathrm{~mL}$ of McIlvaine buffer solution ( $\mathrm{pH}$ 2.2) was added to each tube. The solutions were heated at $40^{\circ} \mathrm{C}$ at suitable time interval (5 minutes). After cooling, the volumes were completed to $10 \mathrm{~mL}$ with distilled water and the first derivative spectra were recorded. The same procedure was repeated at heating temperature $50^{\circ} \mathrm{C}$.

2.6.4. Effect of Acidic, Alkaline, and Oxidative Conditions on Stability of PHZ Standard Solution. $5 \mathrm{~mL}$ of PHZ standard solution $(24.8 \mu \mathrm{g} / \mathrm{mL})$ was placed in 25 volumetric flask. $2 \mathrm{~mL}$ of either $1 \mathrm{M}$ HCL or $0.1 \mathrm{M} \mathrm{NaOH}$ was added and the volume was completed to the mark with distilled water. The solutions were placed at room temperature and heated at $100^{\circ} \mathrm{C}$. The first derivative spectra were recorded every 15 minutes. The effect of oxidative conditions on PHZ was investigated by adding $1 \mathrm{~mL}$ of $1.2 \mathrm{M} \mathrm{H}_{2} \mathrm{O}_{2}$ to $3 \mathrm{~mL}$ PHZ standard solution $(24.8 \mu \mathrm{g} / \mathrm{mL})$. The volume was completed to $10 \mathrm{~mL}$ with distilled water and first derivative spectra were recorded every day for three days.

2.6.5. Effect of Light on PHZ Standard Solution. PHZ standard solution $(7.49 \mu \mathrm{g} / \mathrm{mL})$ was placed in transparent and amber glass tubes. The solutions were then subjected to direct sunlight during mid-day time for 4 hours. The degradation process was monitored using the developed method.

\section{Results and Discussion}

3.1. Method Development. The normal spectrum of DD and PHZ mixture revealed $\lambda_{\max }$ at $370 \mathrm{~nm}$ and $241 \mathrm{~nm}$, respectively (Figure 2). Since derivatization of normal spectrum gives rise to reduction of band width, sharper peaks were achieved on first derivative spectrum and DD and PHZ were successfully resolved at $398 \mathrm{~nm}$ and $273 \mathrm{~nm}$, respectively (Figure 3).

3.2. Validation of the Developed Method. The proposed method was validated in accordance with $\mathrm{ICH}$ guidelines by assessment of different parameters [21].

3.2.1. Linearity, $L O D$, and $L O Q$. The developed method was used to construct DD and PHZ standard calibration curves. The linearity data was interpreted at 95\% confidence limit and summarized in Table 1.

According to ICH, linearity parameters that should be estimated are slope, intercept, correlation coefficient, and residual sum of squares. As tabulated above, the correlation coefficient was closer to unity (>0.997). Further, the $95 \%$ confidence interval of the intercept included the theoretical zero which in contrast was not included within slope confidence interval. It was also found that residual sum of squares was closer to zero with residual values that were randomly distributed between negative and positive values. LOD and LOQ values are smaller than a reported chromatographic method [14]. These findings greatly confirmed the linearity of the regression model of first derivative spectrophotometry.
TABLE 1: Linearity data of the developed method.

\begin{tabular}{lcc}
\hline Parameter & DD & PHZ \\
\hline Slope \pm SD & $0.0014 \pm 0.00004$ & $0.0018 \pm 0.00003$ \\
Intercept \pm SD & $-0.0006 \pm 0.0003$ & $-0.0006 \pm 0.0003$ \\
Correlation coefficient $r^{2}$ & 0.9973 & 0.9990 \\
Residual sum of squares & $2.04 \times 10^{-7}$ & $2.08 \times 10^{-7}$ \\
95\% confidence interval & $0.001229-0.001489$ & $0.0017-0.0019$ \\
of the slope & & \\
95\% confidence interval & $-0.00149-0.00025$ & $-0.00148-0.00027$ \\
of the intercept & $0.63 \mu \mathrm{g} / \mathrm{mL}$ & $0.48 \mu \mathrm{g} / \mathrm{mL}$ \\
LOD & $1.92 \mu \mathrm{g} / \mathrm{mL}$ & $1.47 \mu \mathrm{g} / \mathrm{mL}$ \\
LOQ & & \\
\hline
\end{tabular}

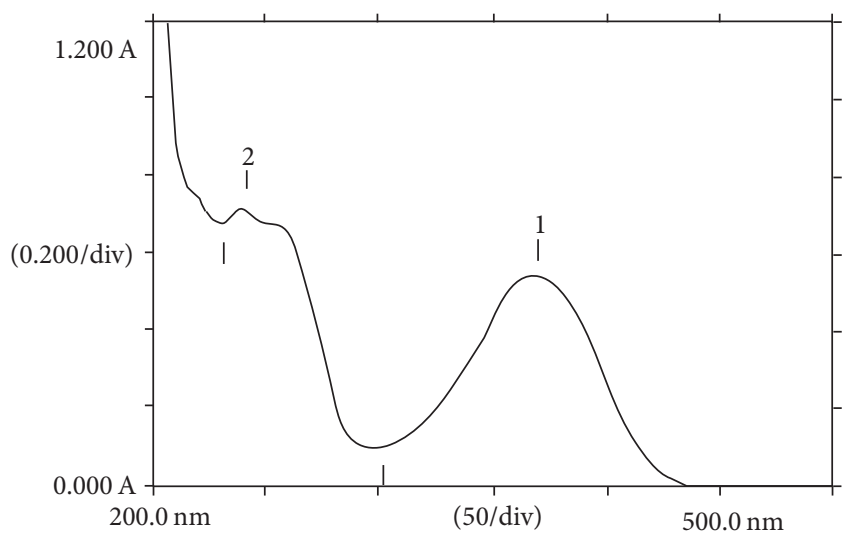

FIgURE 2: Normal spectrum of DD (1) and PHZ (2) aqueous mixture.

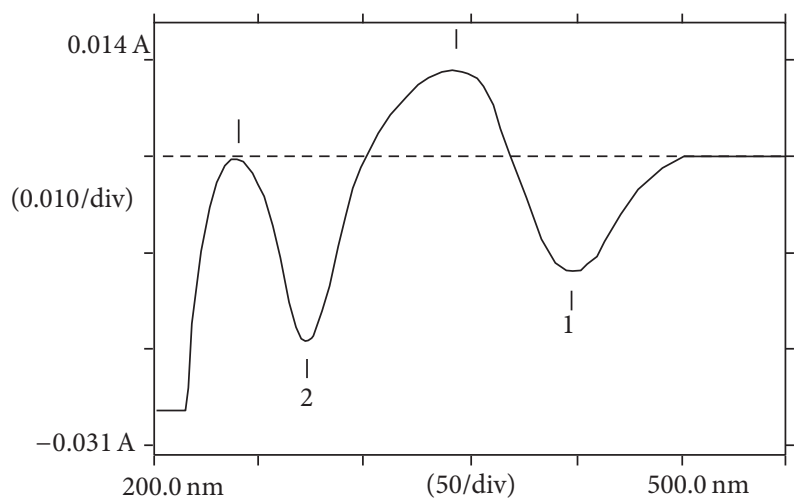

FIGURE 3: First derivative spectrum of DD (1) and PHZ (2) aqueous mixture.

The content uniformity of sample was analysed using the developed method where good results were obtained $(100.12 \% \pm 1.45 \% ; 100.11 \% \pm 0.82 \% ; n=3)$ for DD and PHZ, respectively.

3.2.2. Precision and Accuracy. Precision studies revealed RSD\% values within acceptable limits $(<3 \%)$ reflecting the precision and robustness of the method within the selected range (Table 2). The results of "\% recovery" were between 88.32\% and $90.96 \%$ for DD and between $96.84 \%$ and $101.12 \%$ for PHZ which in turn reflected the accuracy of the method. 
TABLE 2: Within-day and between-day precision data for DD and PHZ.

\begin{tabular}{lccc}
\hline Drugs & $\begin{array}{c}\text { Concentration } \\
(\mu \mathrm{g} / \mathrm{mL})\end{array}$ & Within-day RSD\% & Between-day RSD\% \\
\hline \multirow{2}{*}{$\mathrm{DD}$} & 6 & 2.13 & 0.81 \\
& 8 & 1.74 & 0.79 \\
& 10 & 0.51 & 2.68 \\
\hline \multirow{3}{*}{$\mathrm{PHZ}$} & 7.49 & 1.46 & 0.40 \\
& 9.98 & 1.43 & 0.44 \\
& 12.48 & 0.39 & 0.98 \\
\hline
\end{tabular}

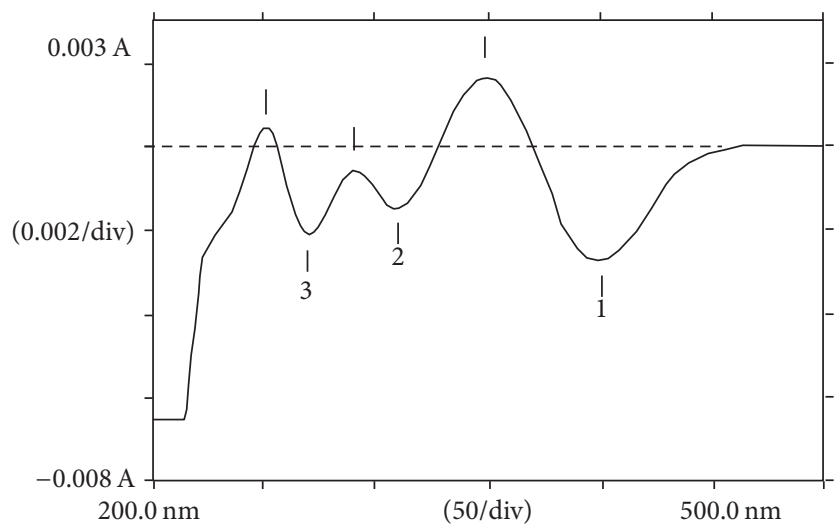

FIGURE 4: First derivative spectrum of DD (1) and its degradation products $(2,3)$ in acidic conditions.

3.3. Stability Studies on $D D$. Forced degradation conditions were employed to investigate stability of DD, stability indicating power, and specificity of the developed method. The effect of different acid concentrations at different time intervals on DD degradation rate was investigated using the developed method. The first derivative spectrum of DD solution treated with $0.05 \mathrm{M} \mathrm{HCL}$ reflected a decrease in its peak at $398 \mathrm{~nm}$ with appearance of well resolved degradation products peaks at $313 \mathrm{~nm}$ and $271 \mathrm{~nm}$ (Figure 4). The presence of triazene bridge in DD structure allows it to be susceptible for degradation. These degradation products were already confirmed to be 4-aminobenzamidine and 4-hydroxybenzamidine [16]. The degradation rate was calculated from the plot of $\log \%$ remained drug versus time interval (Figure 5) and found to follow first-order kinetics. Values of $t_{1 / 2}$ and $t_{90}$ were found to decrease with increased time.

The degradation process was monitored at different temperatures $\left(40^{\circ} \mathrm{C}\right.$ and $\left.50^{\circ} \mathrm{C}\right)$ using the developed method. The linear plot of $\log \%$ remained versus time interval (Figure 6) indicated the dependence of degradation rate and consequently $t_{1 / 2}$ and $t_{90}$ on temperature (Table 3 ). Arrhenius plot (Figure 7) was used to calculate the activation energy $(7.48 \mathrm{kcal} / \mathrm{mole})$ which was then utilized to calculate $t_{1 / 2}$ and $t_{90}$ at different temperatures.

The developed method was also applied to study the effect of alkali, hydrogen peroxide, and light on degradation of DD.
TABLE 3: Effect of temperature on DD degradation rate.

\begin{tabular}{lccc}
\hline Temp. & Rate constant $\left(\mathrm{min}^{-1}\right)$ & $t_{1 / 2}$ (min.) & $t_{90}$ (min.) \\
\hline $25^{\circ} \mathrm{C}$ & 0.024 & 28.88 & 4.38 \\
$40^{\circ} \mathrm{C}$ & 0.075 & 9.24 & 1.04 \\
$50^{\circ} \mathrm{C}$ & 0.108 & 6.42 & 0.97 \\
\hline
\end{tabular}

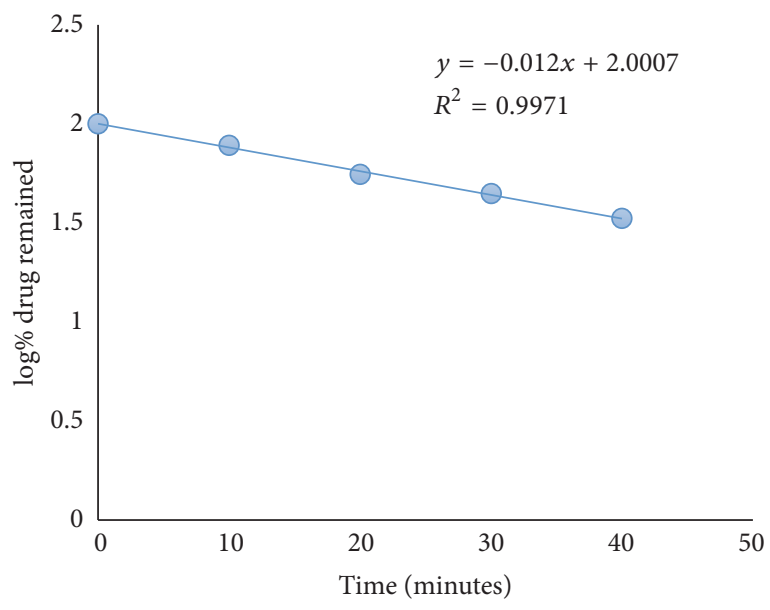

FIGURE 5: Degradation of DD in acidic conditions (0.05 M).

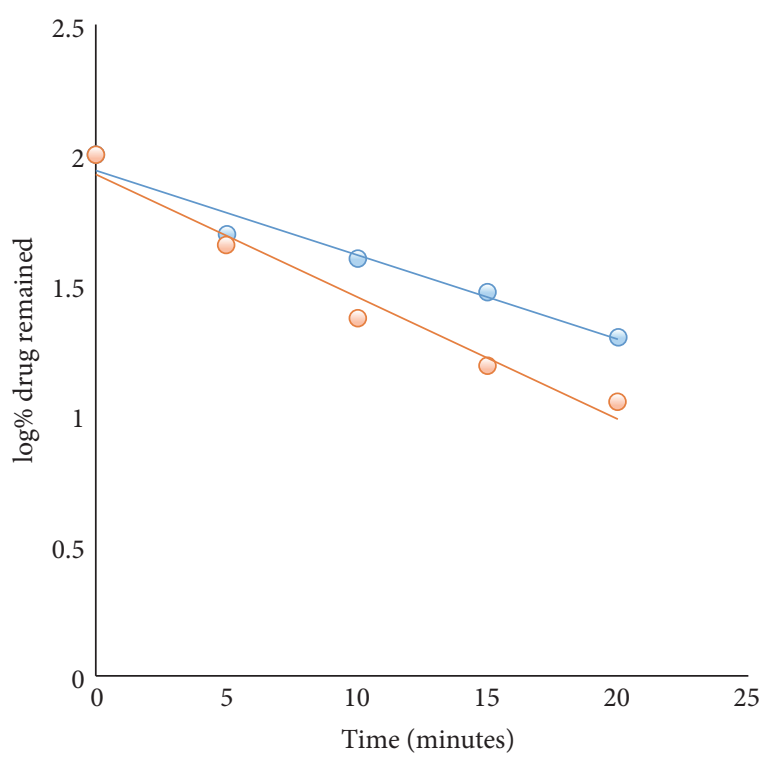

FIGURE 6: Effect of temperature $\left(40^{\circ} \mathrm{C}, 50^{\circ} \mathrm{C}\right)$ on the degradation of DD in acidic conditions.

No degradation products were observed under study conditions. Nevertheless, remarkable decrease in DD quantity (66.67\%) was observed upon exposure to direct sunlight. Thus, protection from direct light is highly recommended for reconstituted samples. Decrease in DD quantity was also observed within two days; however, addition of PHZ stabilized DD wet sample for two weeks. 


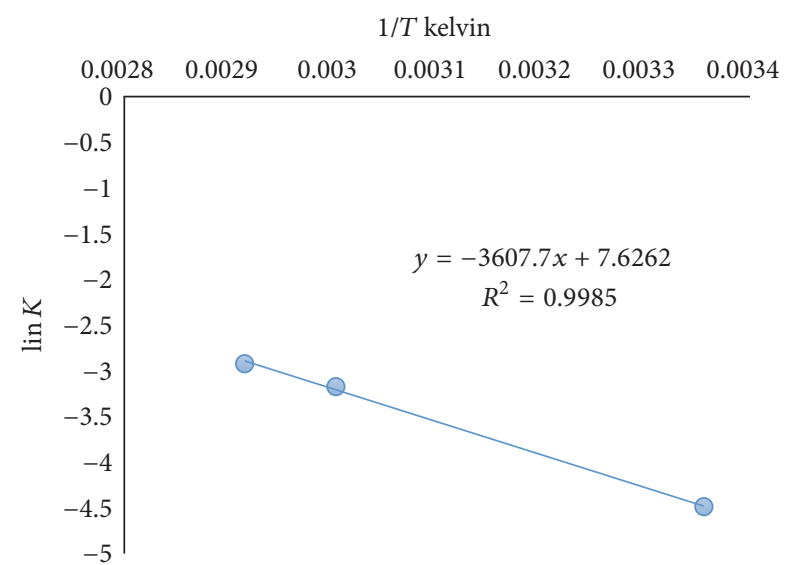

Figure 7: Arrhenius plot for degradation of DD at $40^{\circ} \mathrm{C}$ and $50^{\circ} \mathrm{C}$.

3.4. Stability Studies on PHZ. Contrary to DD, PHZ was proved to be stable under alkaline, acidic, oxidative, and photolytic conditions even at high temperature.

\section{Conclusions}

An accurate, precise, and feasible first derivative spectrophotometric method was developed for simultaneous determination of DD and PHZ in bulk and pharmaceutical dosage forms. The method was proved to be stability indicating and successfully resolved DD in the presence of its degradation products. The degradation of DD under acidic condition and its photo-instability were confirmed while $\mathrm{PHZ}$ was found to be stable under all the study conditions. Thus, the developed method could be successfully used for stability studies and routine quality control analysis of both drugs.

\section{Competing Interests}

The authors declare that there is no conflict of interests regarding the publication of this paper.

\section{References}

[1] S. C. Sweetman, Ed., Martindale: The Complete Drug Reference, Pharmaceutical Press, London, UK, 36th edition, 2009.

[2] European Pharmacopoeia Commission, European pharmacopoeia 5.0, pp. 2217-2218, 2005.

[3] M. N. Abualhasan, N. Batrawi, A. N. Zaid, and D. G. Watson, "A validated and stability indicating HPLC method for analysis of diminazene aceturate and antipyrine combination in a ready injectable solution," Drug Research, vol. 63, no. 6, pp. 300-304, 2013.

[4] Y. O. Aliu, M. Mamman, and A. S. Peregrine, "Pharmacokinetics of diminazene in female Boran (Bos indicus) cattle," Journal of Veterinary Pharmacology and Therapeutics, vol. 16, no. 3, pp. 291-300, 1993.

[5] S. B. Turnipseed, S. B. Clark, W. C. Andersen, C. M. Karbiwnyk, K. E. Miller, and J. A. Hurlbut, "Confirmation of diminazene diaceturate in bovine plasma using electrospray liquid chromatography-mass spectrometry," Journal of Chromatography B: Analytical Technologies in the Biomedical and Life Sciences, vol. 844, no. 1, pp. 127-133, 2006.

[6] M. W. Teunissen, J. E. Meerburg-van der Torren, N. P. Vermeulen, and D. D. Breimer, "Automated high-performance liquid chromatographic determination of antipyrine and its main metabolites in plasma, saliva and urine, including $4,4^{\prime}$ dihydroxy-antipyrine," Journal of Chromatography B: Biomedical Sciences and Applications, vol. 278, pp. 367-378, 1983.

[7] M. Danhof, E. De Groot-Van Der Vis, and D. D. Breimer, "Assay of antipyrine and its primary metabolites in plasma, saliva and urine by high-performance liquid chromatography and some preliminary results in man," Pharmacology, vol. 18, no. 4, pp. 210-223, 1979.

[8] H. G. Fouda, "Gas chromatography chemical ionization mass spectrometric analysis of diminazene in plasma," Biological Mass Spectrometry, vol. 5, no. 1, pp. 72-75, 1978.

[9] C. Staiger, J. de Vries, and E. Walter, "A rapid and sensitive method for the determination of phenazone (antipyrine) using gas-liquid-chromatography with nitrogen detection," Journal of Clinical Chemistry and Clinical Biochemistry, vol. 18, no. 11, pp. 817-819, 1980.

[10] S. A. Staroverov, O. A. Vasilenko, K. P. Gabalov et al., "A competitive enzyme-linked immunosorbent assay for diminazene," International Immunopharmacology, vol. 8, no. 2, pp. 75-81, 2002.

[11] R. J. Gilbert, "Studies in rabbits on the disposition and trypanocidal activity of the antitrypanosomal drug, diminazene aceturate (Berenil)," British Journal of Pharmacology, vol. 80, no. 1, pp. 133-139, 1983.

[12] R. L. Chang, A. W. Wood, W. R. Dixon et al., "Antipyrine: radioimmunoassay in plasma and saliva following administration of a high dose and a low dose," Clinical Pharmacology \& Therapeutics, vol. 20, no. 2, pp. 219-226, 1976.

[13] C. Atsriku, D. G. Watson, J. N. A. Tettey, M. H. Grant, and G. G. Skellern, "Determination of diminazene aceturate in pharmaceutical formulations by HPLC and identification of related substances by LC/MS," Journal of Pharmaceutical and Biomedical Analysis, vol. 30, no. 4, pp. 979-986, 2002.

[14] L. Kassaye, A. Hymete, A. A. Bekhit, and G. Genete, "Validation of an HPLC method for the simultaneous determination of diminazene diaceturate and phenazone in injectable veterinary granules and bulk powders," Pakistan Journal of Pharmaceutical Sciences, vol. 25, no. 1, pp. 255-259, 2012.

[15] E. Dinç, M. Kanbur, and D. Baleanu, "Comparative application of wavelet approaches to absorption and ratio spectra for the simultaneous determination of diminazene aceturate and phenazone in veterinary granules for injection," Pharmazie, vol. 60, no. 12, pp. 892-896, 2005.

[16] M. Campbell, R. J. Prankerd, A. S. Davie, and W. N. Charman, "Degradation of berenil (diminazene aceturate) in acidic aqueous solution," Journal of Pharmacy and Pharmacology, vol. 56, no. 10, pp. 1327-1332, 2004.

[17] H.-F. Miao, M. Cao, D.-Y. Xu et al., "Degradation of phenazone in aqueous solution with ozone: influencing factors and degradation pathways," Chemosphere, vol. 119, pp. 326-333, 2015.

[18] A. J. Owen, Uses of Derivative Spectroscopy. Spectroscopy, 8 pages, 1995.

[19] T. C. Mcllvaine, "A buffer solution for colorimetric comparison," The Journal of Biological Chemistry, vol. 49, no. 1, pp. 183-186, 1921. 
[20] M. Mutasim Elimam, S. Wagiealla Shantier, E. Ahmed Gadkariem, and M. Awadalla Mohamed, "Derivative spectrophotometric methods for the analysis and stability studies of colistin sulphate," Journal of Chemistry, vol. 2015, Article ID 624316, 5 pages, 2015.

[21] ICH Topic Q2 (ICH), "Validation of analytical procedures: text and methodology," in Proceedings of the International Conference on Harmonisation of Technical Requirements for Registration of Pharmaceuticals for Human Use, Chicago, Ill, USA, 2005. 

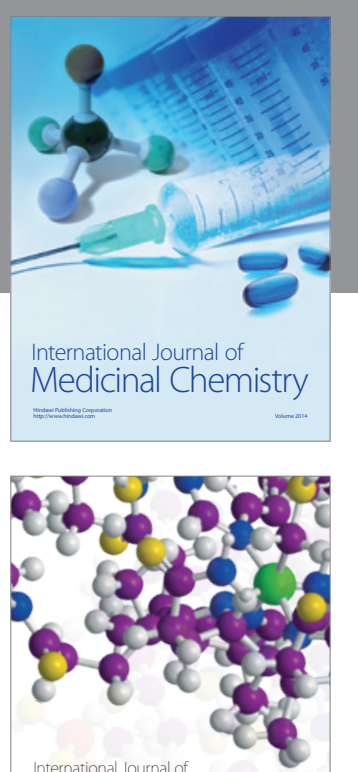

Carbohydrate Chemistry

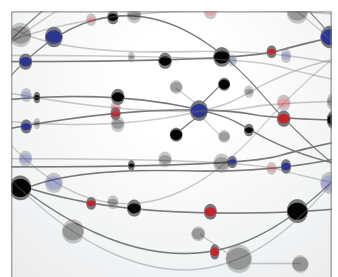

The Scientific World Journal
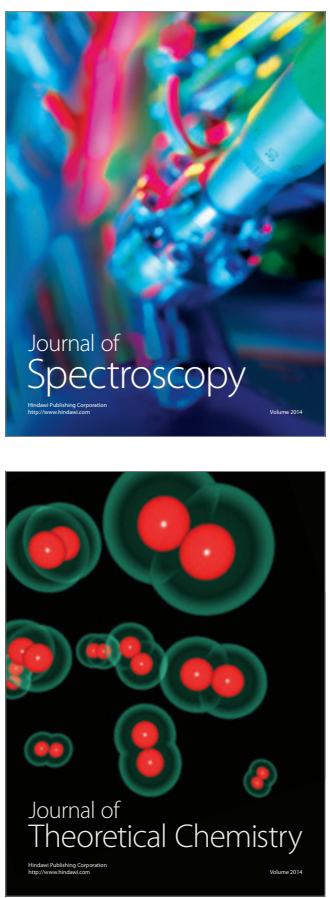
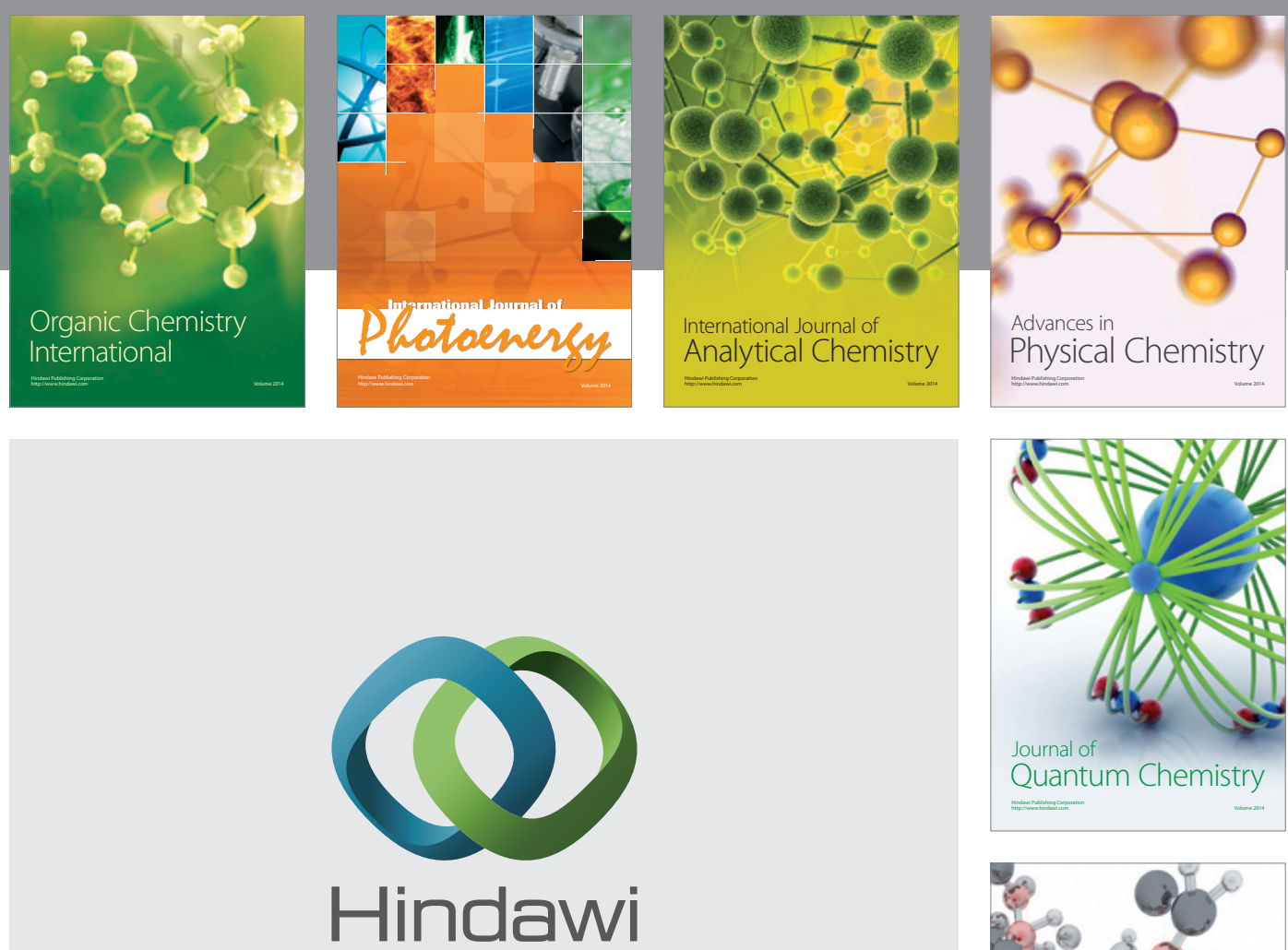

Submit your manuscripts at

https://www.hindawi.com

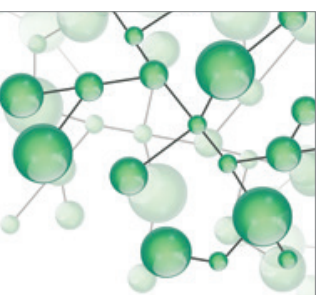

International Journal of

Inorganic Chemistry
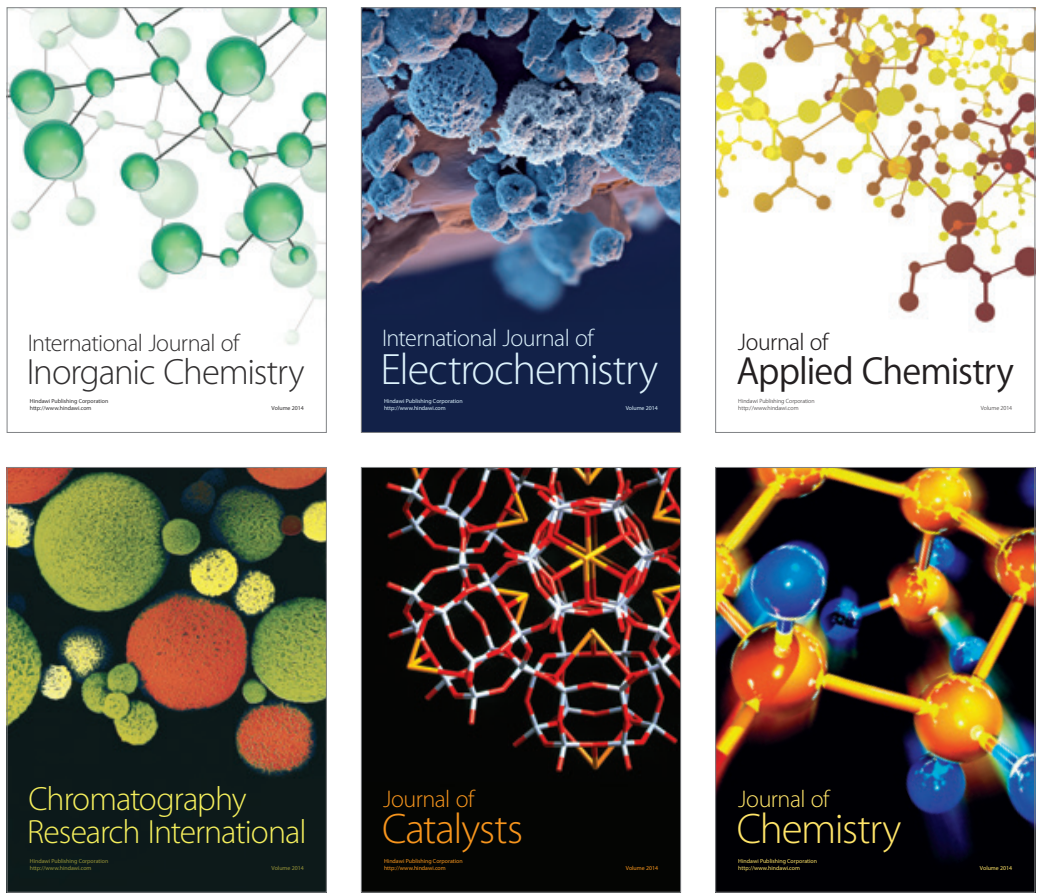

Journal of

Applied Chemistry
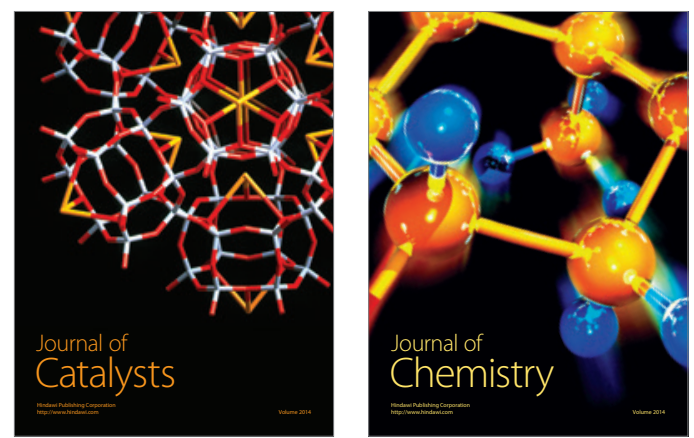
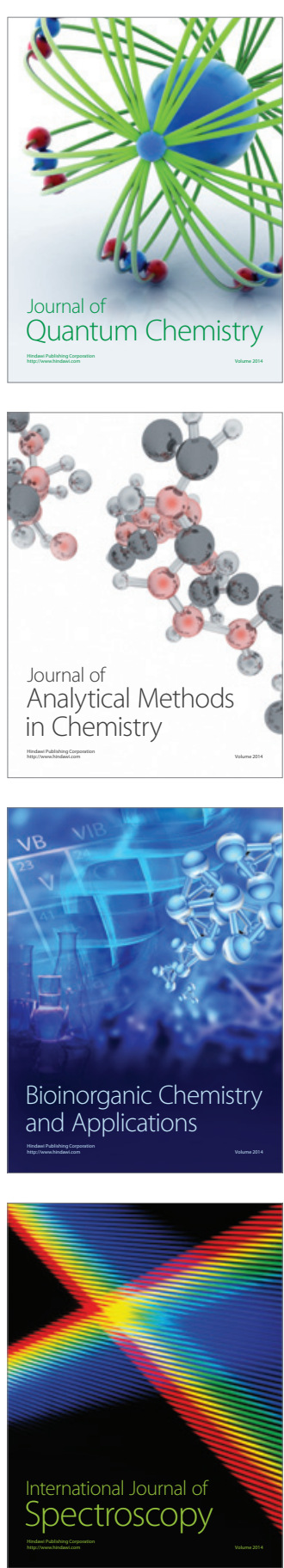